\title{
CARICA PAPAYA MEDIATED GREEN SYNTHESIZED SILVER NANOPARTICLES
}

\author{
A. ANBARASU*, P. KARNAN, N. DEEPA, R. USHA. \\ Department of Zoology, Presidency College, Chennai 600005 \\ Email: a.anbarasu141981@gmail.com
}

Received: 21 Jan 2018, Revised and Accepted: 08 Mar 2018

\begin{abstract}
Objective: The present study was designed to biosynthesize NPs from leaves to study the reducing Ag+ions and stabilizing the particles and confirm AgNP synthesis by using various spectroscopy and microscopic methods.

Methods: Bio-inspired AgNPs were rapidly synthesized at room temperature using fresh aqueous leaf extract of Carica papaya. A green and lowcost synthesis was effective in the formation of stable crystalline NPs in the solution. Amine, alkene and alkyl halides groups present in the Carica papaya leaf extract functioned as reducing as well as a stabilizing agent to produce shape controlled AgNPs.

Results: SPR confirmed the formation of AgNPs in UV-Visible spectra at $445.7 \mathrm{~nm}$. The XRD result also showed the presence of elemental Ag+as a crystalline nature. Study the functional groups responsible for the bio reduction of Ag+. HE-TEM and FE-SEM with EDX image showed spherical crystalline AgNPs.
\end{abstract}

Conclusion: Hence, the plant-based bio AgNPs could be used in biomedical applications.

Keywords: Carica papaya, Biosynthesis, AgNPs, HE-TEM, XRD, FE-SEM and EDX

(C) 2018 The Authors. Published by Innovare Academic Sciences Pvt Ltd. This is an open access article under the CC BY license (http://creativecommons.org/licenses/by/4.0/] DOI: http://dx.doi.org/10.22159/ijcpr.2018v10i3.27221

\section{INTRODUCTION}

Nanomedicine is an emerging field expanding rapidly because of the development and incorporation of new nanocomposites into a range of products and technologies. In recent years, the application of nanoparticles (NPs) in medicine has increased and expanded to the fields of molecular imaging [1], drug delivery [2], diagnosis and treatment of cardiovascular diseases [3], wound healing [4] and development of materials and medical devices with antimicrobial properties [5].

New applications of NPs and nanomaterials are emerging rapidly in biomedical sciences [6]. This decade has witnessed the inception of new significant technological products particularly based on nanotechnology; NPs synthesis is being widely explored since they exhibit unique size and shape dependent properties for applications in optics, electronics, catalytic systems, magnetic and biomedical fields such as HIV inhibition, cancer cell cytotoxicity and genotoxicity [7]. Apart from this, recently the anti-tumour effect of AgNPs has been reported against different cancerous cell lines [8]. NPs with the size range between 1 and $1000 \mathrm{~nm}$ are mainly explored for the diagnosis and treatment of human cancers, which led to the new discipline of nano-oncology [9].

There are a number of methods used for the synthesis of silver nanoparticles (AgNPs) including physical and chemical methods [10-13], electrochemical reduction $[14,15]$, photochemical reduction [16] and thermal evaporation [17-18]. However, a rapid and green synthesis method using plant extract has developed an enormous interest in AgNPs synthesis due to green chemistry approach. Moreover, it is simple, cost-effective, eco-friendly, easily scaled up for large-scale synthesis, without using toxic and redundant chemicals in solid, liquid and gaseous form [19]. Indeed, a number of bacteria [20], fungi and yeast have been wellknown for the synthesis of non-toxic noble NPs [21]. However, the microbial-mediated synthesis of NPs is not industrially feasible as it requires expensive medium and maintenance of highly aseptic conditions [22].

In this context, plant-mediated NPs synthesis seems to be a costeffective as well as eco-friendly method. Moreover, NP synthesis from plants with medicinal properties proves to be beneficial in treating various ailments in a better and easy way. On such plant is Papaya, a tropical fruit, often seen in orange-red, yellow-green and yellow-orange hues with a rich orange pulp. Whole plant parts, fruits, roots, bark, peel, seeds and pulp are known to have medicinal properties. It has been used for the treatment of numerous diseases like warts, corns, sinuses, eczema, cutaneous tubercles, blood pressure, dyspepsia, constipation, amenorrhea, general debility, expel theard worms and stimulate reproductive organs [23]. It also effectively trats and improves all types of digestive and abdominal disorders [24-27]. Leaves of papaya, one of the plant part with numerous medicinal value have the history of streaming and eating with spinach in Asia [23]. It has found to have a significant effect on various tumor cell lines and the tea extract of leaves found to have antimicrobial, ease menstrual pain, relieve nausea, increase the appetite and antispasmodic activities [23]. Phytochemical investigations were carried out on this plant by several authors, which revealed the presence of carbohydrates, phenols, flavonoids, sterols, alkaloids, saponins, cardiac glycosides, ecdysterone etc., from different parts of this plant. Survey of the literature revealed that NPs synthesis from Carica papaya leaves is scanty. In view of this, the present study was designed to biosynthesize NPs from leaves to study the reducing Ag+ions and stabilizing the particles and confirm AgNP synthesis by using various spectroscopy and microscopic methods.

\section{MATERIALS AND METHODS}

Collection and identification

Fresh leaves of Carica papaya were collected from Presidency College, Chennai, Tamil Nadu, India, and were authentically identified by Dr. P. Jayaraman, Chennai, India, Carica papaya as (Caricaceae) with voucher specimen no: 123/PARC/2017.

\section{Preparation of leaf extract and synthesis of AgNPs}

Twenty grams of fresh leaves were washed thoroughly in tap water and distilled water for $30 \mathrm{~min}$. in order to remove the debris. The aqueous extract was prepared by taking $25 \mathrm{~g}$ of washed and finely chopped leaves in $100 \mathrm{ml}$ conical flask along with $100 \mathrm{ml}$ of distilled water and the mixture was boiled at $45^{\circ} \mathrm{C}$ for $30 \mathrm{~min}$. This aqueous extract was filtered through Whatmann No. 1 filter paper and was used for the synthesis of AgNPs. $10 \mathrm{ml}$ of this aqueous leaf extract 
was added to $90 \mathrm{ml}$ of $1 \mathrm{mmol}$ aqueous silver nitrate solution for the synthesis of AgNPs. A control setup silver nitrate was also maintained without Carica papaya extract.

\section{Qualitative phytochemical analysis}

Qualitative phytochemical analysis of aqueous extract was carried out by the method of Harborne (1973) [28]

\section{Characterization of silver NPs}

UV-Visible spectra were recorded as a function of the reaction time on PG Instruments spectroscopy. The studi es on size, morphology and composition of the NPs were performed by means of HR-TEM (PHILIPS TECNAI 10) and FE-SEM with EDX (Carl Zesis). The purified AgNPs were examined for the presence of biomolecules using FTIR analysis. Briefly, the spectrum obtained from the dried sample was recorded on FT-IR spectrum (Perkin-Elmer, USA) in the diffuse reflectance mode at a resolution of $4 \mathrm{~cm}-1$ in $\mathrm{KBr}$ pellets. Particle size analyzer was done dynamic light scattering (Malvern, MAL 1062727, UK). Crystalline AgNPs were determined by XRD. Briefly, the biosynthesized AgNPs were laid onto glass substrates on
Phillips PW 1830 instrument operating at a voltage of $40 \mathrm{kV}$ and current of $30 \mathrm{~mA}$ with $\mathrm{Cu} \mathrm{K} \alpha 1$ radiation.

\section{RESULTS AND DISCUSSION}

The present study was aimed to identify the phytocompounds present in Carica papaya and to synthesize AgNPs from the aqueous extract of Carica papaya leaves which is distributed as a weed throughout India. Phytochemical study of Carica papaya leaf extract shows the positive results for carbohydrates, tannins, saponins, phenols, flavonoids, alkaloids, anthocyanin, terpenoids and triterpenoids. On the other hand coumarins and steroids were absent in the aqueous extract (table 1 ).

The bioactive compounds such as polyphenol, carbohydrates, vitamin and trace elements present in the leaf extract plays an important role as an antioxidant, anticancer, antitumor, antiinflammatory, anti-obesity, anti-helminthic, analgesic, antipyretic, anti-nociceptive, anti-hepatitis, hepatoprotective, cardiac, Diuretic agent, attributing platelet augmentation, anticancer property, antiacne activity, easing menstrual pain and relieving nausea. [31-34].

Table 1: Qualitative phytochemical analysis of Carica papaya aqueous extract

\begin{tabular}{|c|c|c|}
\hline S. No. & Secondary metabolites & Aqueous extract \\
\hline 1 & Carbohydrate & +++ \\
\hline 2 & Tannins & + \\
\hline 3 & Saponins & +++ \\
\hline 4 & Flavonoids & +++ \\
\hline 5 & Alkaloids & +++ \\
\hline 6 & Anthocyanin & + \\
\hline 7 & Quinones & + \\
\hline 8 & Glycosides & - \\
\hline 9 & Cardiac glycosides & ++ \\
\hline 10 & Terpenoids & + \\
\hline 11 & Triterpenoids & ++ \\
\hline 12 & Phenols & +++ \\
\hline 13 & Coumarins & - \\
\hline 14 & Acids & + \\
\hline 15 & Protein & + \\
\hline 16 & Steroids & - \\
\hline
\end{tabular}

++Strongly positive++Positive+Trace-Not detected

\section{UV-vis analysis of green phyto-synthesized solutions}

The aqueous extracts of papaya leaves (Carica papaya) when mixed in an aqueous solution of silver ion complex, the reduction of pure $\mathrm{Ag}^{+}$ions to $\mathrm{Ag}{ }^{\circ}$ was monitored by measuring
UV-vis spectrum of the reaction media. The reduction of silver nitrate into AgNPs during exposure to plant extract is followed by a gradual increase in colour development from clear to drak brown colour, as a result of the surface plasmon resonance phenomenon (fig. 1).

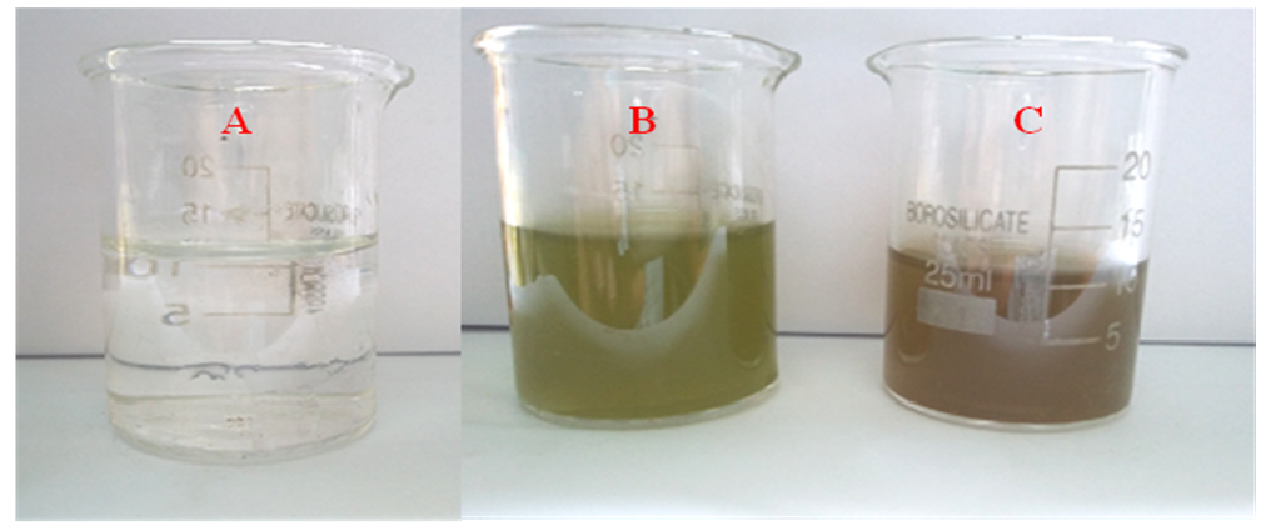

Fig. 1A: Color intensity of 1 mmol $\mathrm{AgNO}_{3}$ solution, B. Aqueous extract of Carica papaya (pale light green colour), C. AgNPs synthesized at different hours with pale light green colour to dark brown colour 
The UV-visible spectral analysis of (Carica papaya) without AgNO3 did not show any change in colour. The UV-vis spectra of all the samples exhibited distinct surface plasmon resonance bands. The position of plasmon resonance band in UV-vis spectra is sensitive to particle shape, size, its interaction with the medium and the extent of charge transfer between medium and the particles. Here, the sharp bands were centered at $445.7 \mathrm{~nm}$ in (Carica papaya) AgNPs extract clearly indicate the presence of silver nanoparticles (fig. 2).
Similarly, AgNPs synthesized by using aqueous extract of Sargassum polycystum showed absorbance at $430 \mathrm{~nm}$ [35], Sargassum longifolium showed absorbance peak at $460 \mathrm{~nm}$ [36], Eucalyptus hybrid [37], Acalypha indica [38], Solanum tarvum [39], Helianthus annus [40], and Cassia auriculata [41], the absorbance peaks were between 400 and $450 \mathrm{~nm}$. When compared with these plants and seaweeds, AgNPs synthesized from an aqueous extract of Carica papaya were active at the relatively lower wavelength.
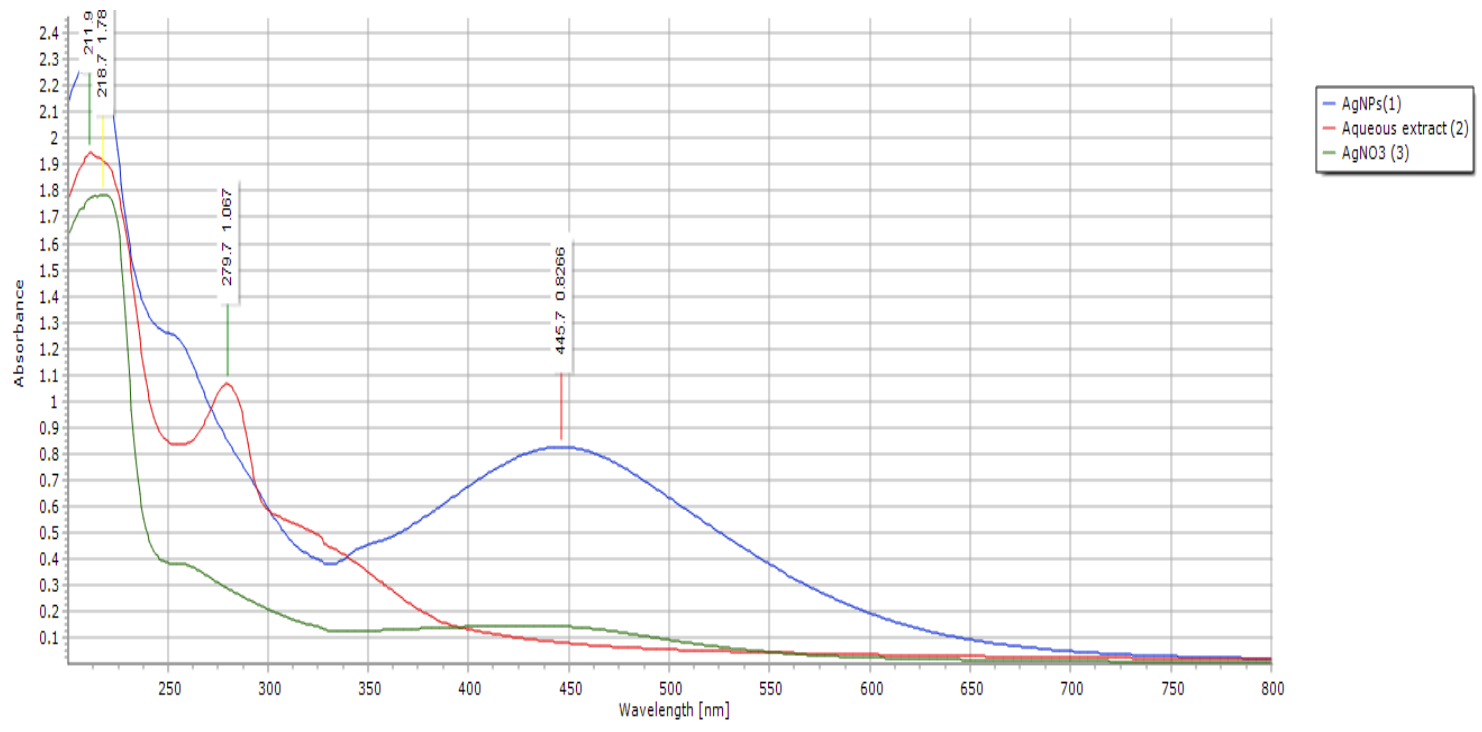

Fig. 2: UV-Vis spectral image of Carica papaya aqueous extract based synthesized silver nanoparticles

\section{XRD spectral analysis}

Insert fig. 3 shows the XRD pattern of Carica papaya aqueous extract based synthesized silver nanoparticles which exhibits strong and broad diffraction peaks at and $=\theta 224.9$ 41.30. The four other characteristic peaks showed in the case of $\mathrm{Ag}{ }^{\circ}$ nanocomposite hydrogel indicates the face-centred cubic (fcc) structure. The diffraction peaks at and $=\theta 238.9,44.62$ and 64.9 corresponding to the reflections of crystal planes ( $\left(\begin{array}{lll}1 & 1 & 1\end{array}\right),\left(\begin{array}{lll}2 & 0 & 0\end{array}\right)$ and $\left(\begin{array}{lll}2 & 2 & 0\end{array}\right)$ respectively. This face-centred cubic (fcc) structure indicates that Ag0 nanoparticles were dispersed in the Carica papaya aqueous extract based synthesized silver nanoparticles by the bioreduction method. Similar results were reported by [42, 43], these author's biosynthesized AgNPs using Cinnanonum camphora and marine algae (Sargassum polycystum and Sargassum longifolium) extract compound respectively.

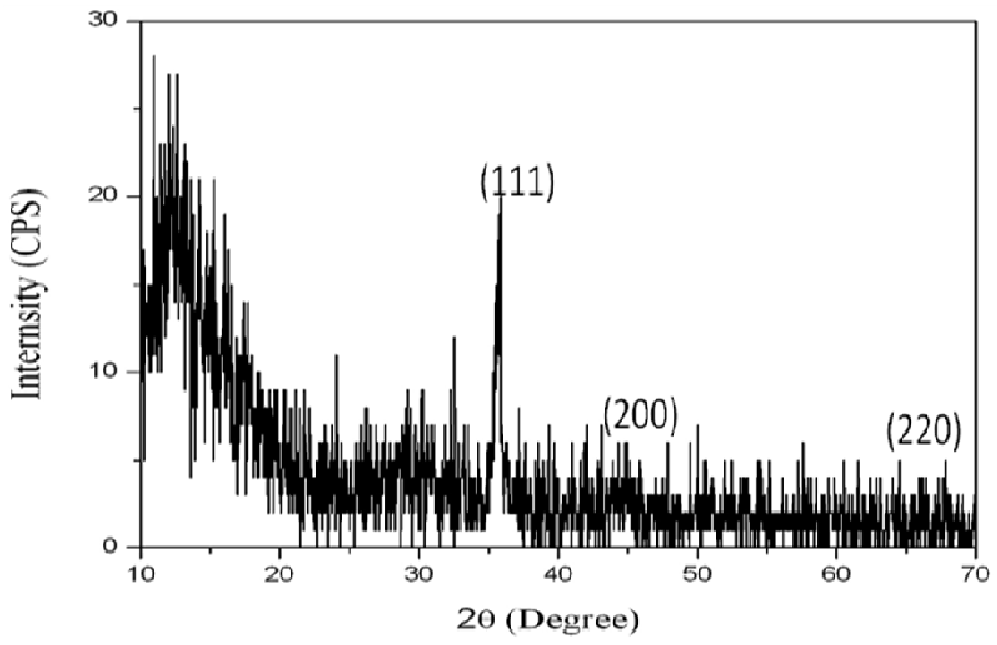

Fig. 3: XRD pattern of Carica papaya aqueous extract based synthesized silver nanoparticles

\section{HR-TEM and FE-SEM analysis}

HR-TEM analyses showed the particle size $10 \mathrm{~nm}$ with a spherical morphology and the SAED pattern reveals that nanoparticles are polydispersive in nature (fig. $4 \mathrm{~A}$ and $\mathrm{B}$. The FESEM image of synthesized silver nanoparticles also showed the sperical shaped nanoparticles with the aggregation (fig. 5).
The EDX spectrum also confirms the bio reduction of silver nanoparticles with the peaks of silver and oxygen and this may be due to the surface plasmon resonance (SPR) (fig. 6). The FESEM image has clearly proved the bio reduction of $\mathrm{Ag}^{+}$to $\mathrm{Ag}{ }^{\circ}$ by the formation of spherical ovoid morphology. Overall the size and morphology distribution of AgNPs was found to be below $100 \mathrm{~nm}$. 


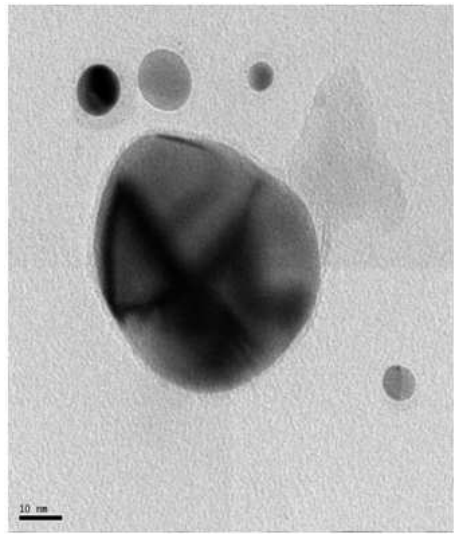

A

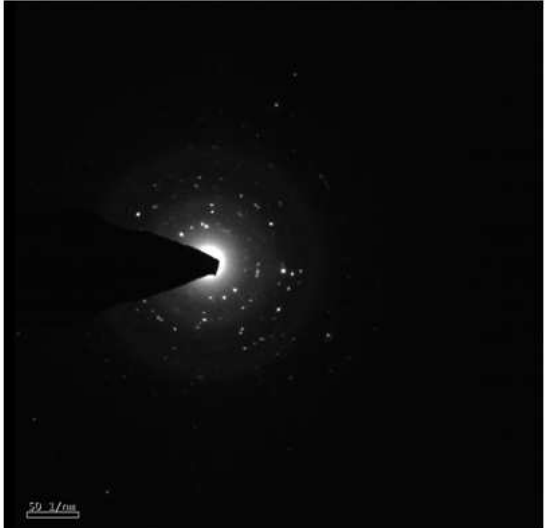

B

Fig. 4: A-HR-TEM image of Carica papaya aqueous extract based synthesized silver nanoparticles and the B-SAED pattern image of Carica papaya aqueous extract based synthesized silver nanoparticles

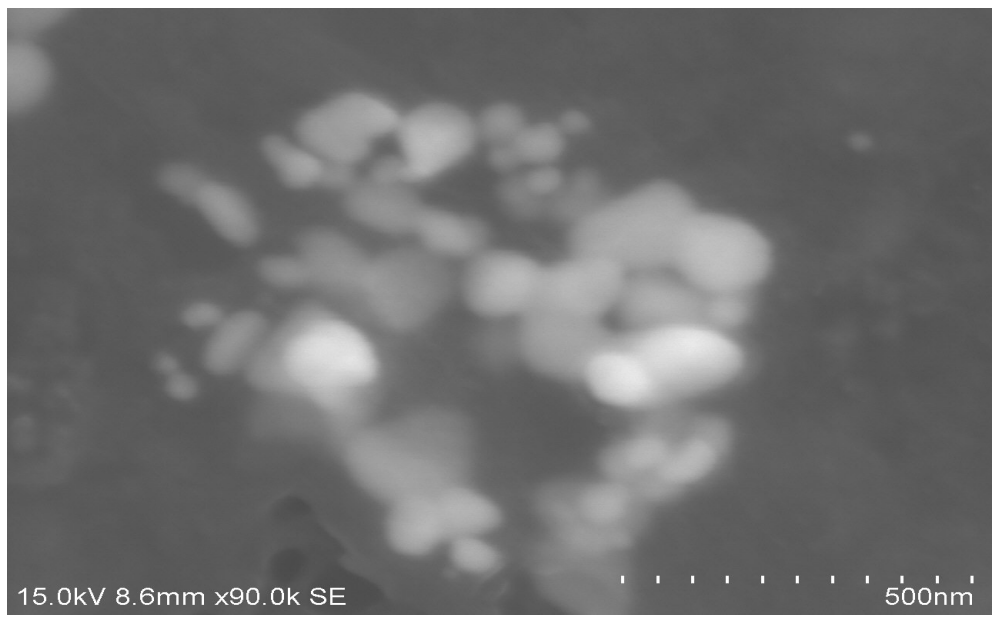

Fig. 5: FE-SEM image of Carica papaya aqueous extract based synthesized silver nanoparticles

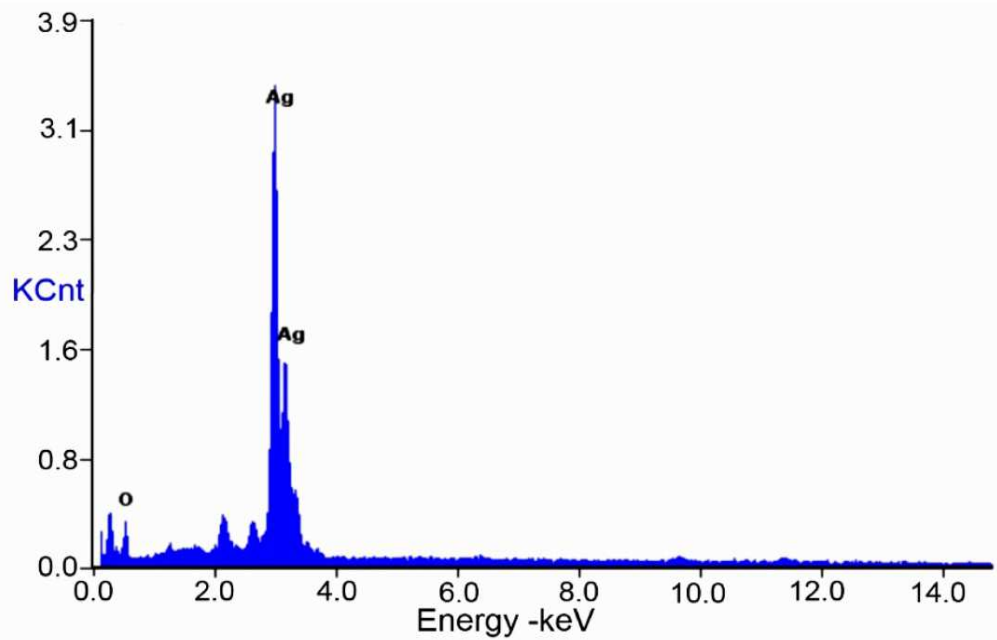

Fig. 6: EDX Characterization spectrum obtained for Carica papaya aqueous extract based synthesized silver nanoparticles

\section{CONCLUSION}

In this paper, we have reported cost-effective and eco-friendly bio reducing method for synthesizing silver NPs using fresh leaves aqueous extract. These biologically synthesized silver NPs play a crucial role in protecting our environment as green. UV-Vis spectroscopy revealed the surface plasmon property, while TEM and SEM with EDX image revealed the nano nature of the prepared sample. The structural analysis by XRD strongly suggests the formation of elemental silver NPs instead of their oxides in 
biosynthesized NPs. The XRD structural analysis of AgNPs showed that they were crystalline in nature, which might be due to the presence of bio reduction of AgNPs. Therefore, the use of natural antioxidants for the synthesis of AgNPs seems to be a good alternative which could be attributed to its benign composition. The plant material responsible for the reduction and stabilization of nanoparticle needs further study including extraction and identification of the bioactive compounds presented in the extract.

\section{AUTHORS CONTRIBUTIONS}

All the author have contributed equally

\section{CONFLICT OF INTERESTS}

Declared none

\section{REFERENCES}

1. Kohl Y, Kaiser C, Bost W, Stracke F, Fournelle M, Wischke C. Preparation and biological evaluation of multifunctional PLGANPs designed for photoacoustic imaging. Nanomed 2011;7:228-37.

2. Meng $\mathrm{H}$, Liong $\mathrm{M}, \mathrm{Xia} \mathrm{T}, \mathrm{Li} \mathrm{Z}$, Ji Z. Engineered design of mesoporous silica NPs to deliver doxorubicin and Pglycoprotein siRNA to overcome drug resistance in a cancer cell line. ACS Nano 2010;4:4539-50.

3. Godin B, Sakamoto JH, Serda RE, Grattoni A, Bouamrani A, Ferrari M. Emerging applications of nanomedicine for the diagnosis and treatment of cardiovascular diseases. Trends Pharmacol Sci 2010;31:199-205.

4. Tian J, Wong KK, Ho CM, Lok CN, Yu WY, Che CM. Topical delivery of silver NPs promotes wound healing. Chem Med Chem 2007;2:129-36.

5. Rangari VK, Mohammad GM, Jeelani S, Hundley A, Vig K, Singh SR. Synthesis of Ag/CNT hybrid NPs and fabrication of their nylon-6 polymer nanocomposite fibers for antimicrobial applications. Nanotechnology 2010;21:95-102.

6. Yu DG. Formation of colloidal silver NPs stabilized by Na+poly $(\gamma$-glutamic acid)-silver nitrate complex via chemical reduction process. Colloids Surf B 2007;59:171-8.

7. Tan Y, Wang Y, Jiang L. Thiosalicylic acid-functionalized silver NPs synthesized in the one-phase system. J Colloid Interface Sci 2002;249:336-45.

8. Petit C, Lixon P, Pileni MP. In situ synthesis of silver nanocluster in AOT reverse micelles. Phys Chem 1993;97:12974-83.

9. Vorobyova SA, Lesnikovich AI, Sobal NS. Preparation of silver NPs by interphase reduction. Colloids Surf A 1999;152:375-9.

10. Saha S, Sarkar J, Chattopadhyay D, Patra S, Chakraborty A, Acharya K. Production of silver NPs by a phytopathogenic fungus Bipolaris nodulosa and its antimicrobial activity. Digest J Nanomaterials Biostructures 2010;5:887-95.

11. Sandmann G, Dietz H, Plieth W. Preparation of silver NPs on ITO surfaces by a double-pulse method. J Electroanal Chem 2000;491:78-86.

12. Mallick K, Witcombb MJ, Scurrella MS. Self-assembly of silver NPs in a polymer solvent: formation of a nanochain through nanoscale soldering. Mater Chem Phys 2005;90:221-4.

13. Bae CH, Nam SH, Park SM. Formation of silver NPs by laser ablation of a silver target in $\mathrm{NaCl}$ solution. Appl Surf Sci 2002;197:628-34.

14. Smetana AB, Klabunde KJ, Sorensen CM. Synthesis of spherical NPs. J Colloid Interface Sci 2005;284:521-6.

15. Saxena A, Tripathi RM, Singh RP. Biological synthesis of silver NPs by using onion (Allium cepa) extract and their antibacterial activity. Digest J Nanomaterials Biostructures 2010;5:427-32.

16. Priyadarshini $S$, Gopinath V, Meera Priyadarshini N, Mubarak Ali D, Velusamy P. Bio-inspired green NPs: synthesis, mechanism, and antibacterial application. Colloids Surf B 2013;102:232-7.

17. Fayaz AM, Girilal M, Rahman M, Venkatesan R, Kalaichelvan PT. Biogenic synthesis of silver NPs and their synergistic effect with antibiotics: a study against gram-positive and gramnegative bacteria. Process Biochem 2011;46:1958-62.

18. Laldhas KP, Cheriyan VT, Puliappadamba VT, Bava SV, Unnithan RG, Vijayammal PL, et al. Green synthesis of silver NPs using herbal plants. J Cell Mol Med 2010;14:636-46.
19. Song JY, Kim BS, Rapid biological synthesis of silver NPs using plant leaf extracts. Bioprocess Biosyst Eng 2008;32:79-84.

20. Murphy CJ. Sustainability as an emerging design criterion in nanoparticle synthesis and applications. J Mater Chem 2008;18:2173-6.

21. Mubarak Ali D, Thajuddin N, Jeganathan K, Gunasekaran M. Plant-mediated synthesis of silver and gold NPs and its antibacterial activity against the clinically isolated pathogen. Colloids Surf B 2011;85:360-5.

22. Kumar V, Yadav SK. Plant-mediated synthesis of silver and gold NPs and their applications. J Chem Technol Biotechnol 2009;84:151-7.

23. Akhila S, Vijayalakshmi NG. Phytochemical studies on Carica papaya leaf juice. Int J Pharm Sci Res 2015;6:880-3.

24. Aravind G, Debjit B, Duraivel S, Harish G. Traditional and medicinal uses of Carica papaya.J Med Plants Studies 2013;1:7-15.

25. Jaime AT, Zinia R, Duong TN, Dharini S, Abed G, Manoel TS, et al. Papaya: biology and biotechnology. Tree Forestry Sci Biotechnol 2007;1:47-73.

26. Natarajan S, Vidhya RM. Potential medicinal properties of Carica papaya Linn-a mini review. Int J Pharm Pharm Sci 2014;6:1-4.

27. Parle M, Guruditta. Basketful benefits of papaya. Int Res J Pharm 2011;2:6-12.

28. Harborne JB. In: "Phytochemical Methods". Ed. $1^{\text {st }}$ Edn. Chapman and Hall Ltd., London; 1973. p. 49-188.

29. Mosmann T. Rapid colorimetric assay for cellular growth and survival: Application to proliferation and cytotoxicity assays. J Immunol Methods 1983;65:55-63.

30. Rajesh S, Sivakumari K, Ashok K, Abitha AR. Anticancer activity of Cardiospermum helicacacabum leaf extracts against hepatocellular carcinoma cell line (HepG-2). World J Pharm Sci 2016;5:1133-54.

31. Saad A, Siddiqui MMH, Aleem S, Jafri SAH. Effect of namak chirchita (Achyranthes aspera Linn.) in zeeq-un-nafs sho'bi (Bronchial Asthma). Hamdard Medicus 2002;45:37-40.

32. Shah GB, Parmar NS. Antiasthmatic property of polyherbal preparation E-721. Phytother Res 2003;17:1092-7.

33. Goyal BR, Mahajan SG. The beneficial effect of Achyranthes apsera L. in Toluene-di-isocyanate induced occupational asthma in rats. Global J Pharmacol 2007;1:6-12.

34. Aswal BS, Goel AK, Kulshrestha DK, Mehrotra BN, Patnaik GK. Screening of Indian plants for biological activity. Ind J Exp Biol 1996;34:444-67.

35. Saha S, Sarkar J, Chattopadhyay D, Patra S, Chakraborty A, Acharya K. Production of silver nanoparticles by a phytopathogenic fungus Bipolaris nodulosa and its antimicrobial activity. Digest J Nanomaterials Biostructures 2010;5:887-95.

36. Mosmann T. Rapid colorimetric assay for cellular growth and survival: Application to proliferation and cytotoxicity assays. J Immunol Methods 1983;65:55-63.

37. Manikandan R, Beulaja M, Arulvasu C, Sellamuthu S, Dinesh D, Prabhu D, et al. the Synergistic anticancer activity of Curcumin and Catechin: an in vitro study using human cancer cell lines. Microsc Res Tech 2012;75:112-6.

38. Rajesh S, Sivakumari K, Ashok K, Abitha AR. Anticancer activity of Cardiospermum helicacacabum leaf extracts against hepatocellular carcinoma cell line (HepG-2). World J Pharm Sci 2016;5:1133-54.

39. Asha Kanimozhi S, Johnson M, Renisheya Joy Jeba Malar T. Phytochemical composition of Sargassum polycystum C. agardh and Sargassum duplicatum J. agardh. Int J Pharm Pharm Sci 2012;7:393-7.

40. Rajeshkumar S, Malarkodi C, Vanaja M, Paulkumar K. Greenchemical fabrication of silver nanoparticles by marine macroalgae and its fungicidal activity. Int Res J Pharm Biosci 2014;1:1-7.

41. Suriya J, Bharathi Raja S, Sekar V, Rajasekaran R. Biosynthesis of silver nanoparticles and its antibacterial activity using seaweed Urospora sp. Afr J Biotechnol 2012;11:12192-8.

42. Huang J, Li Q, Sun D, Lu Y, Su Y, Yang X, et al. Biosynthesis of silver and gold NPs by novel sundried Cinnanonum camphora leaf. Nanotechnology 2007;18:105104-14. 
43. Ankamwar B, Damle C, Ahmad A, Sastry M. Biosynthesis of Au and AgNPs using Emblica officinalis fruit extract, their phase transfer and transmetallation in an organic solution. J Nanosci Nanotechnol 2005;5:1665-7. 